\title{
Effect of adjuncts on microbiological and chemical properties of Scamorza cheese
}

\author{
Angela Guidone, ${ }^{*}$ Ada Braghieri, ${ }^{*}$ Silvia Cioffi, ${ }^{*}$ Salvatore Claps, $†$ Francesco Genovese, ${ }^{*}$ Giuseppe Morone, $\dagger$ \\ Fabio Napolitano, * and Eugenio Parente*1 \\ *Scuola di Scienze Agrarie, Forestali, Alimentari ed Ambientali, Università degli Studi della Basilicata, 85100 Potenza, Italy \\ †Consiglio per la Ricerca e la Sperimentazione in Agricoltura, Unità di ricerca per la Zootecnia Estensiva, 85054 Muro Lucano (PZ), Italy
}

\begin{abstract}
Scamorza is a semi-hard, pasta filata cheese resembling low-moisture Mozzarella cheese, with a short ripening time $(<30 \mathrm{~d})$. Scamorza has a bland flavor and, to provide diversification from similar cheeses, it was manufactured using 2 types of milk in the current study: 100\% Italian Friesian milk (F) or 90\% F and $10 \%$ Jersey cow milk (mixed, M), and 2 types of starter: Streptococcus thermophilus or S. thermophilus with peptidolytic Lactococcus lactis, Lactobacillus helveticus, and Lactobacillus paracasei strains as adjuncts). The cheeses were ripened for $30 \mathrm{~d}$. The adjunct did not significantly affect acid production or growth of the primary starter; 2 of the species used in the adjunct ( $L b$. paracasei and $L b$. helveticus) rapidly colonized the cheese and persisted until the end of ripening, whereas the counts of nonstarter lactic acid bacteria in the control cheese were low until the end of ripening. The use of adjuncts affected $\mathrm{pH}$, microbial composition (as assessed by both culture-dependent and cultureindependent methods), total free amino acid content, and volatile profile (measured using an electronic nose), whereas milk type had only a minor effect. Although differences in primary proteolysis were found, they were probably indirect and related to the effects on $\mathrm{pH}$ and moisture. We conclude that, even with a short ripening time $(30 \mathrm{~d})$, use of a peptidolytic adjunct may significantly affect important features of Scamorza and may be used to create a product that is measurably different from competing products.
\end{abstract}

Key words: pasta filata cheese, Scamorza, adjunct, proteolysis, aroma

\section{INTRODUCTION}

A large variety of pasta filata cheeses (De Angelis and Gobbetti, 2011) are produced in Italy from cow and

Received July 1, 2014.

Accepted November 22, 2014.

${ }^{1}$ Corresponding author: eugenio.parente@unibas.it buffalo milks. Although some cheeses have a protected designation of origin (e.g., fresh cheeses such as Mozzarella di Bufala Campana, and semi-hard or hard cheeses such as Provolone Valpadana, Caciocavallo Silano, Provolone del Monaco, Ragusano; http://ec.europa.eu/ agriculture/quality/door/list.html) according to standards of identity that require the use of raw milk and natural starter cultures or no added starter (Randazzo et al., 2002; Piraino et al., 2005; Aponte et al., 2008; Ercolini et al., 2008; De Angelis and Gobbetti, 2011; De Filippis et al., 2014), several others, including several fresh, semi-hard, and hard varieties, are produced using either direct acid addition or defined starter cultures composed of Streptococcus thermophilus alone or in combination with thermophilic lactobacilli (De Angelis and Gobbetti, 2011). Scamorza and Provola are 2 shortripened varieties that have evolved from traditional cheeses produced throughout southern Italy (Baruzzi et al., 2002; Cronin et al., 2007); they are similar in texture to low-moisture Mozzarella cheese (Kindstedt, 2004; Kindstedt et al., 2004) and are used as table cheese or pizza topping. Due to their short ripening time $(<30$ d), these cheeses cannot undergo significant proteolysis compared with cheeses with longer ripening times (such as Caciocavallo and Provolone; Gobbetti et al., 2002; Piraino et al., 2005). Use of adjunct cultures is a common method to accelerate ripening of cheese (Chamba and Irlinger, 2004), and proteolysis, peptidolysis, and AA metabolism are 3 important functions of adjuncts, which can be used as viable or attenuated cultures, the latter to minimize their interference with starter activity (El Soda et al., 2000). Mesophilic nonstarter lactic acid bacteria (NSLAB) such as Lactobacillus casei, Lactobacillus paracasei, Lactobacillus rhamnosus, and Lactobacillus plantarum are most frequently used as adjuncts in several cheese types (El Soda et al., 2000; Chamba and Irlinger, 2004); however, Lactobacillus helveticus (Kenny et al., 2006; Lee et al., 2007) and wild Lactococcus lactis strains (Ayad et al., 2000) have also been used. Cheese aroma is complex and derives from several biochemical and chemical processes (Marilley and Casey, 2004). Metabolism of AA from starter and 
nonstarter bacteria provides a significant contribution (Yvon and Rijnen, 2001; Chamba and Irlinger, 2004; Marilley and Casey, 2004). Different types of adjuncts have been shown to significantly affect the volatile compounds of several cheeses (Ayad et al., 2000; Lee et al., 2007; Van Hoorde et al., 2010).

Curd stretching in hot water, a characteristic step of pasta filata cheese making, may significantly reduce the viability and activity of starter and nonstarter bacteria (Coppola et al., 2006) at the beginning of ripening, although the effect may be influenced by different process parameters, such as screw speed and stretching temperature (Yun et al., 1995; Petersen et al., 2000). Adjunct cultures have been used with some success to accelerate the ripening of a hard pasta filata cheese (Caciocavallo Pugliese; Morea et al., 2007; Di Cagno et al., 2012) with a significant increase in secondary proteolysis. Stretching curd in hot water causes significant starter lethality, but autochthonous $L b$. paracasei adjuncts were found to grow well in cheese and contribute to proteolysis. With the exception of the use of probiotic adjuncts (Albenzio et al., 2013a,b), no study concerning Scamorza cheese has been published on this subject.

The most common dairy cattle breed in Italy is the Italian Friesian. Despite the high production level of the breed, the milk is characterized by a moderate DM content, which may limit cheese yield. Consequently, many farmers include in the herd animals (5 to $20 \%$ of herd) that produce less milk but with higher DM content. Because of their low maintenance requirements and high adaptability to different environmental conditions (e.g., the hilly areas of southern Italy), Italian Jersey cows are often used to this aim.

Perna et al. (2014) showed that cow genetic type (Italian Friesian vs. Italian Brown) significantly affected the gross composition of Caciocavallo cheese produced using raw milk and a natural starter culture. Caciocavallo cheese produced with milk from Italian Brown cows showed higher moisture and a consequent higher proteolysis, although the role of autochthonous NSLAB was not evaluated. De Marchi et al. (2008) evaluated the effect of milk type (Holstein Friesian and Swiss Brown, used alone or in 50:50 mixtures) on the quality of 3 Italian cheeses (Casoletti, Vezzena, and Grana Trentino) and found that milk type significantly affected yield, color, and FA composition, with intermediate values between the 2 milk types for 50:50 mixtures.

The objective of this study was to evaluate the effect of milk type and addition of a peptidolytic adjunct culture on microbiological and chemical properties of Scamorza cheese. In addition, the effect on production of volatile compounds was evaluated. The adjunct included 3 strains (Lc. lactis C4F11, Lb. helveticus L206, and $L b$. paracasei C3D7), which had been selected in a previous study on pasta filata cheeses because of their proteolytic, peptidolytic, and autolytic properties (Piraino et al., 2008). The effect on sensory properties and consumer liking is reported in the companion paper (Braghieri et al., 2015).

\section{MATERIALS AND METHODS}

\section{Starter Cultures}

A direct-to-vat freeze-dried culture of Streptococcus thermophilus (Lyofast ST051, Sacco Srl, Cadorago, Italy) was used for all cheeses as directed by the manufacturer. The use of ST051 alone (ST) was compared with the use of ST051 plus an adjunct culture $(\mathbf{S T}+\mathbf{A})$. The adjunct was prepared by cultivating Lc. lactis ssp. lactis $\mathrm{C} 4 \mathrm{~F} 11$ and $L$ b. helveticus L206 in reconstituted (11\% wt/vol) skim milk (Oxoid, Basingstoke, UK) for $16 \mathrm{~h}$ at 30 and $37^{\circ} \mathrm{C}$, respectively, and $L b$. paracasei ssp. paracasei C3D7 in reconstituted skim milk containing $0.5 \%$ glucose and $0.25 \%$ yeast extract (Oxoid) for $16 \mathrm{~h}$ at $30^{\circ} \mathrm{C}$. All strains were previously isolated from traditional pasta filata cheeses and were selected for their technological properties (Piraino et al., 2008). The cultures were frozen at $-24^{\circ} \mathrm{C}$ until needed, and viable cells after thawing were measured by plate count in LM17 (M17 + 0.5\% lactose, $\left.30^{\circ} \mathrm{C}, 48 \mathrm{~h}\right)$ for $\mathrm{C} 4 \mathrm{~F} 11$ and in de Man, Rogosa, and Sharpe (MRS) agar (48 h, $37^{\circ} \mathrm{C}$ ) for L206 and C3D7. Before use, the cultures were mixed to obtain an adjunct with $10^{8} \mathrm{cfu} / \mathrm{mL}$ with equal proportions of the 3 strains and inoculated in cheese milk at $0.2 \%$.

\section{Cheese-Making Trials and Experimental Design}

Cheese-making trials were carried out according to a randomized block design using four 40-L vats on each cheese-making day, with 3 replicates. The cheese vats were fully automated and each had its own set of tools for mixing, cutting, and raking the curd; vats and tools were thoroughly sanitized before each trial. Two types of milk were used: $100 \%$ from Italian Friesian cattle (F) and mixed milk containing 90\% from Italian Friesian cattle $+10 \%$ Jersey $(\mathbf{M})$, both obtained from 2 local dairy farms (one providing the Italian Friesian milk and one providing the Jersey cattle milk). The milk was not standardized. Each was inoculated with 1 of 2 starters (ST or $\mathrm{ST}+\mathrm{A}$ ), and the 4 treatments were designated FST, FST+A, MST, and MST+A. Milk composition was determined using a Milkoscan FT1 (Foss Italia, Padova, Italy).

The cheese-making recipe for Scamorza, a semihard pasta filata cheese, was used. The milk was heat treated 
at $65^{\circ} \mathrm{C}$ for $10 \mathrm{~min}$ and cooled at $38^{\circ} \mathrm{C}$. Liquid veal rennet $(1: 18,000$, Caglificio Clerici SpA, Cadorago, Italy) was added $(30 \mathrm{~mL} / 100 \mathrm{~L}$ of milk). Coagulation occurred within 16 min and the curd was manually cut to $2 \mathrm{~cm}$. Cooking was immediately started under agitation until a temperature of $42^{\circ} \mathrm{C}$ was reached. The curd was then ripened under whey until the $\mathrm{pH}$ for stretching (5.2) was reached $(2.8 \mathrm{~h}$ after the addition of rennet). Stretching and molding were performed manually $\left(85^{\circ} \mathrm{C}, 10 \mathrm{~min}\right)$ to obtain pear-shaped cheeses with a small head (fresh weight of $500 \mathrm{~g}$ ). After cooling in tap water $(1 \mathrm{~h})$, the cheese was salted in brine $(20 \% \mathrm{NaCl}$, $2 \mathrm{~h}$ ) and ripened at 10 to $12^{\circ} \mathrm{C}$ and 75 to $80 \%$ relative humidity for $30 \mathrm{~d}$. Samples were taken at 0 (curd), 0.2 (immediately after salting), 7, 15, and $30 \mathrm{~d}$ for chemical and microbiological analyses. At the end of ripening, the cheeses were vacuum packaged and stored at $4^{\circ} \mathrm{C}$.

\section{Gross Composition of Cheeses and Proteolysis}

The $\mathrm{pH}$ of cheeses was measured using a spear-tip electrode (Hamilton Bonaduz AG, Bonaduz, Switzerland) and a pH meter (Orion 420A plus, Thermo Fisher Scientific, Rodano, Italy). Moisture (\% wt/wt) was measured by oven drying (IDF, 1982) and chlorides by a potentiometric method (Fox, 1963). Fat in cheese was measured using a standard method (IDF, 1996).

The $\mathrm{pH} 4.6$-soluble and $\mathrm{pH} 4.6$-insoluble fractions of cheese at 7 and $15 \mathrm{~d}$ were obtained using the method of Kuchroo and Fox (1982). Free AA were measure using the trinitro-benzene-sulfonic acid (TNBS) method (Adler-Nissen, 1979) on the $\mathrm{pH}$ 4.6-soluble fraction. The $\mathrm{pH}$ 4.6-insoluble fraction was freeze-dried and used to assess primary proteolysis by urea-PAGE as previously described (Piraino et al., 2005). After staining with Coomassie Brilliant Blue (Blakesley and Boezi, 1977), the gels were digitized to TIFF (.tif) images using a scanner.

\section{Microbial Counts}

Microbial counts were performed on milk, milk after the addition of starter, curd before stretching, and on cheeses at 7, 15, and $30 \mathrm{~d}$. Cheese samples were homogenized in $2 \%$ (wt/vol) trisodium citrate solution and further decimal dilutions were prepared in sterile quarter-strength Ringer's solution; all dilutions were carried out in Ringer's for milk samples. Total mesophilic counts were carried out by pour plating in standard plate count agar (PCA, Oxoid) after $48 \mathrm{~h}$ at $30^{\circ} \mathrm{C}$. Thermophilic streptococci were enumerated in LM17 agar (M17 broth, Oxoid, with 1\% lactose and $1.2 \%$ agar bacteriological) after incubation for $2 \mathrm{~d}$ at $42^{\circ} \mathrm{C}$. Nonstarter lactic acid bacteria were differentially enumerated in modified MRS with bromophenol blue (mMRS-BPB; Lee and Lee, 2008) after incubation under anaerobiosis (GenBox Jars, bioMérieux Italia, Firenze, with AnaeroGen bags, Oxoid) at 25 or $37^{\circ} \mathrm{C}$ for $48 \mathrm{~h}$. Coliforms were enumerated in milk and cheese by pour-plating on violet red bile agar (Oxoid), after incubation for $24 \mathrm{~h}$ at $37^{\circ} \mathrm{C}$.

\section{DNA Extraction and PCR-Denaturing Gradient Gel Electrophoresis}

First, DNA was extracted from a 1:4 suspension of cheese in 2\% (wt/vol) trisodium citrate using Power food Bacterial DNA Extraction kit (MoBio Laboratories Inc., Carlsbad, CA; Quigley et al., 2012) as described in the manufacturer's instructions. Then, PCR-denaturing gradient gel electrophoresis (PCRDGGE) of the V3 region of $16 \mathrm{~S}$ ribosomal DNA was carried out as described by Ercolini et al. (2004) but Q5 Hot Start High-Fidelity DNA Polymerase (New England Biolabs, Ipswich, MA) was used, and staining was performed using $25 \mu \mathrm{L}$ of SYBR Gold $10,000 \times$ (Invitrogen, Thermo Fisher Scientific, Rodano, Italy) in 250 $\mathrm{mL}$ of Tris-acetate EDTA buffer (TAE $1 \times$ ). Gel images were digitized using a GelDocXR apparatus with and XcitaBlue conversion screen, ChemiDoc XRS filter, and Quantity One 1-D analysis software (Bio-Rad Laboratories, Hercules, CA) and converted to TIFF images. For the identification of bands, 2 procedures were used: 2 ladders including amplified DNA from pure cultures of Lb. plantarum DSM20174, Enterococcus faecium DSM20477, Lb. helveticus ATCC15807, Enterococcus faecalis DSM20478, Lc. lactis ssp. lactis DSM20481, and Lb. paracasei DSM5622 were included in all gels, and bands that did not match with those of the ladder were eluted, reamplified using the same primers, checked for purity, and sequenced if a single amplification product was obtained.

\section{Electronic Nose Analysis}

Cheese samples were analyzed using a 10-MOS electronic device (PEN-3, Airsense Analytics GmbH, Schwerin, Germany). The air flux method was used in this trial. The fluxed aroma was obtained using an output needle inserted into a $50-\mathrm{mL}$ Teflon vial containing $1 \mathrm{~g}$ of cheese at $20^{\circ} \mathrm{C}$ with an air flow of $400 \mathrm{~mL} / \mathrm{min}$. The sample run lasted $60 \mathrm{~s}$ and was followed by $300-\mathrm{s}$ flush time. Each measurement, carried out in triplicate, was controlled and recorded in a text file by using WinMunster v.1.6.2.2 software (Airsense Analytics GmbH).

\section{Statistical Analysis}

Statistical analyses were performed using Systat 13 (Systat Software Inc., San Jose, CA) unless otherwise 
stated. Analysis of variance, analysis of covariance (ANCOVA), and multiple mean comparisons with Tukey's honestly significant difference (HSD) test were used to test the significance of differences caused by the treatments and ripening time on gross composition and microbial counts. Multivariate statistical methods-principal component analysis (PCA) and partial least squares (PLS) regression-were used for the analysis of the response of the electronic nose. Image analysis of electrophoretic patterns (PCR-DGGE, urea-PAGE) and band matching were performed using GelCompar II (Applied Maths BV, St-Martens-Latem, Belgium). Cluster analysis (using the Dice coefficient and unweighted pair group method with averages, UPGMA) was used to group PCR-DGGE patterns. The PCA was carried out on relative band intensities in urea-PAGE gels and principal component scores were used in ANOVA.

\section{RESULTS AND DISCUSSION}

\section{Milk Quality and Cheese Composition}

Gross composition of milk was (mean \pm SE for the 3 replicate trials) $3.51 \pm 0.28 \%$ fat, $3.18 \pm 0.10 \%$ protein, and $4.72 \pm 0.09 \%$ lactose for milk from Italian Friesian cows (F), and $5.10 \pm 0.78 \%$ fat, $3.62 \pm 0.18 \%$ protein, and $4.75 \pm 0.10 \%$ lactose for milk from Jersey cows. Consequently, the mixed (M) milk used in cheese making trials was, on average $3.67 \%$ fat, $3.22 \%$ protein, and $4.72 \%$ lactose. The microbiological quality was within legal limits for both milks, with no significant differences among cheese-making trial replicates.

The gross composition of cheese at the end of ripening is shown in Table 1. Significant differences due to milk and milk $\times$ starter interaction were found only for salt in moisture. Significant differences due to starter were found for $\mathrm{pH}$ (lower for cheeses produced with the adjunct) and total free AA (higher for samples produced with the adjunct). Although significant differences in cheese composition as a function of milk type have been found by De Marchi et al. (2008) for Casolet, Vezzena, and Grana Trentino, and by Perna et al. (2014) for Caciocavallo cheese produced with pure milk of different breeds (De Marchi et al., 2008; Perna et al., 2014) or with 50:50 mixtures (De Marchi et al., 2008), the lack of significant differences due to milk type in our study may be caused by the relatively low amount of milk for Jersey cows used in treatments MST and MST $+\mathrm{A}$. Differences in $\mathrm{pH}$ are most likely due to differences in adjunct activity on residuals sugars in the curd, and differences in free AA content were likely due to the higher proteolytic and peptidolytic activity of the adjuncts. The small but systematic differences in salt in moisture content of the cheeses produced with mixed milk are difficult to explain. All cheeses had identical $\mathrm{pH}$ (5.3) at stretching and at brining, and the salt content was not significantly different at 7 and $15 \mathrm{~d}$ (data not shown). Although not significant, the slightly higher fat content of cheese made with mixed milk may have contributed to decreased salt diffusion during brining (Guinee and Fox, 2004), and this difference was significant only at the end of ripening when the loss of moisture was highest.

\section{pH, Microbial Counts, and PCR-DGGE Results}

Evolution of $\mathrm{pH}$ and microbial counts on LM17 and mMRS-BPB are shown in Figure 1. $\mathrm{pH}$ was significantly $(P<0.05)$ lower for cheeses produced with adjuncts from d 7 onward. Counts on LM17 (which reflect the presence of the primary starter, S. thermophilus, at least in the first $15 \mathrm{~d}$ of ripening) were close to $10^{9}$ $\mathrm{cfu} / \mathrm{g}$ throughout ripening. The slight initial decrease may be due to the effect of stretching in hot water. All species of the adjunct grew on mMRS-BPB at $37^{\circ} \mathrm{C}$, as shown by the presence of colonies with the typical morphology of the 3 species used, whereas the primary starter was unable to form colonies on this medium. As expected, counts on mMRS-BPB were significantly higher for the cheeses made with adjuncts until the end of ripening, when high counts were found in all cheeses. Figure 2 shows the proportion of the different species recovered on mMRS-BPB at $30 \mathrm{~d}$, based on colony morphology. Most colonies for all cheeses had the typical morphology of $L b$. paracasei, whereas colonies with the morphology of $L b$. helveticus were detectable for all cheeses made with adjuncts and for one replicate of cheese made with mixed milk without adjuncts. Lactococcus lactis colonies were never found for cheeses made without adjuncts and their proportion was very low (usually $<1 \%$ ) even for cheeses made with adjuncts. To confirm the results of enumerations, total DNA was extracted from cheese at 7 and $30 \mathrm{~d}$ of ripening, and used for PCR-DGGE analysis. An example of a typical gel is shown in Supplementary Figure S1 (http://dx.doi. org $/ 10.3168 / j d s .2014-8554$ ). Except for the bands that matched those of the ladder (all of which were confirmed by extraction, reamplification, and sequencing), other bands were aspecific amplification products or matched the pattern for the $L b$. paracasei group (bands below the $L b$. paracasei band). Cluster analysis of the PCR-DGGE patterns resulted in 3 main clusters and 2 smaller ones (Figure 3). Two main clusters included most of the cheeses produced without the adjunct, and 1 cluster included only 7 -d cheeses in which the only identifiable band was that of the primary starter $(S$. thermophilus), whereas the other included $30-\mathrm{d}$ cheeses 
Table 1. Gross composition, $\mathrm{pH}$, and microbial counts of Scamorza cheeses at $30 \mathrm{~d}$ of ripening (means \pm SE for 3 replicate cheese-making trials)

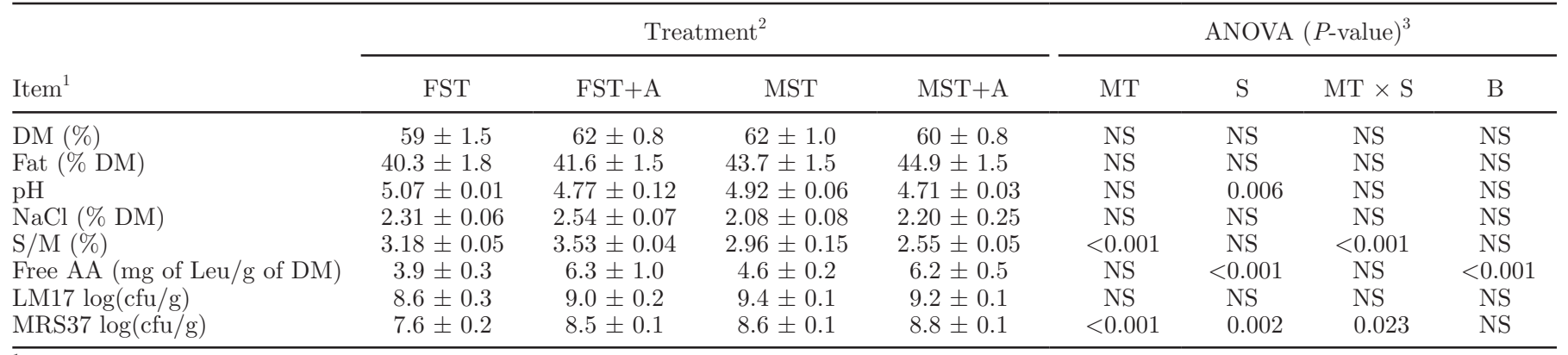

${ }^{1} \mathrm{~S} / \mathrm{M}=$ salt in moisture; LM17 = counts of thermophilic streptococci enumerated on LM17 at $42^{\circ} \mathrm{C} ; \mathrm{MRS} 37=$ counts of nonstarter lactic acid bacteria enumerated on modified de Man, Rogosa, and Sharpe medium with bromophenol blue at $37^{\circ} \mathrm{C}$.

${ }^{2}$ Cheese was made with 2 types of milk: $100 \%$ Italian Friesian milk (F) and mixed milk (M; 90\% F + 10\% Jersey), and 2 types of starter culture: ST, a defined Streptococcus thermophilus starter culture used alone; and ST+A, ST + an adjunct containing Lactococcus lactis, Lactobacillus paracasei, and Lactobacillus helveticus.

${ }^{3}$ The results of ANOVA for milk type $(\mathrm{MT})$, starter $(\mathrm{S})$, interaction $(\mathrm{MT} \times \mathrm{S})$, and block $(\mathrm{B}$, cheese-making day) are shown; NS $=$ nonsignificant $(P>0.05)$.

with the primary starter band and that of the $L b$. casei/ paracasei group. Most of the cheeses produced with the adjunct showed bands for all 3 adjunct species at both 7 and $30 \mathrm{~d}$. One sample (MST replicate 3) produced without adjunct showed $L b$. paracasei and $L b$. helveticus at $7 \mathrm{~d}$, but only the $L b$. paracasei band was present at $30 \mathrm{~d}$. Although contamination of the milk with the adjunct is possible, it is unlikely, because separate tools and closed vats were used for each treatment.

To confirm that the differences in $\mathrm{pH}$ were due to activity of the adjunct, lactose, lactic acid, and acetic acid concentrations were assayed at $15 \mathrm{~d}$. Residual lactose concentrations were (mean $\pm \mathrm{SE}$ for the 3 replicate cheese-making trials) $13.8 \pm 0.07,1.22 \pm 0.07,8.12$ \pm 0.32 , and $2.15 \pm 0.26 \mathrm{~g} / \mathrm{kg}$ of $\mathrm{DM}$ for treatments FST, FST $+\mathrm{A}, \mathrm{MST}, \mathrm{MST}+\mathrm{A}$, respectively. L-Lactic acid concentrations were $13.1 \pm 0.8,14.2 \pm 0.3,15.6$ \pm 0.6 , and $14.6 \pm 1.2 \mathrm{~g} / \mathrm{kg}$ of DM for treatments FST, $\mathrm{FST}+\mathrm{A}, \mathrm{MST}$, and MST $+\mathrm{A}$, respectively, and D-lactic acid concentrations were $<0.2,4.7 \pm 0.3,1.2 \pm 0.1$, and $3.2 \pm 0.2 \mathrm{~g} / \mathrm{kg}$ of DM for treatments FST, FST $+\mathrm{A}$, $\mathrm{MST}, \mathrm{MST}+\mathrm{A}$, respectively. The concentration of acetic acid was below the detection limit of the method used. This pattern confirms that the lower $\mathrm{pH}$ may be due to increased lactose consumption by the DL-lactic acid-producing species ( Lb. helveticus and Lb. paracasei) early during ripening.

Of the 3 adjuncts used, only $2(L b$. helveticus and $L b$. paracasei) were found by both culture-dependent and culture-independent methods. Although we did not use strain typing to confirm that the strains found in cheese were indeed those added with the adjunct, the low numbers of NSLAB found in cheese produced without adjuncts until d 15 suggests that the differences were due to the addition of the adjunct rather than to adventitious NSLAB, which, in contrast, were able to develop to high numbers in all cheeses at $30 \mathrm{~d}$. (Table 1, Figure 1). Lactobacillus helveticus persisted in all cheeses produced with adjuncts until the end of ripening and was also found in a single replicate of cheese produced with mixed milk together with a higher content of $L$. paracasei. This might have been due to contamination with the adjunct during cheese making, although this is unlikely, or to a higher NSLAB content in the milk (microbial counts of the Jersey milk for this single replicate were significantly higher). In the cheeses produced without adjunct, only bands identified as $S$. thermophilus were found in 7 -d cheeses, whereas in 30-d cheese, a band corresponding to the $L b$. casei group was always found. Our results are similar to those obtained for Caciocavallo Pugliese produced with adjuncts (Di Cagno et al., 2012) in which the addition of viable adjuncts resulted in high numbers $\left(>10^{8} \mathrm{cfu} / \mathrm{g}\right)$ of mesophilic lactobacilli early during ripening $(15 \mathrm{~d})$, whereas the number of mesophilic NSLAB was significantly lower in control cheese and increased to values close to $10^{7}$ only after $30 \mathrm{~d}$ of ripening. Nonstarter lactic acid bacilli and $L b$. helveticus are frequently found in ripened pasta filata cheeses (Gobbetti et al., 2002; Piraino et al., 2005). Although the latter are not dominant in the mature cheese, they have been shown to survive and contribute to proteolysis in other semi-hard cheeses (Kenny et al., 2006). Lactococcus lactis has also been found as a subdominant species of the microbiota of ripened pasta filata cheeses (Piraino et al., 2005) but is apparently outnumbered during cheese ripening (Aponte et al., 2008). Its lack of ability to colonize the cheese may be either due to a lower survival to the stretching conditions or to a low competitiveness on the cheese matrix.

Lower $\mathrm{pH}$ is frequently observed in cheese produced with NSLAB adjuncts (Ong et al., 2006, 2007; Ciocia et al., 2013), usually due to the production of acetic acid 

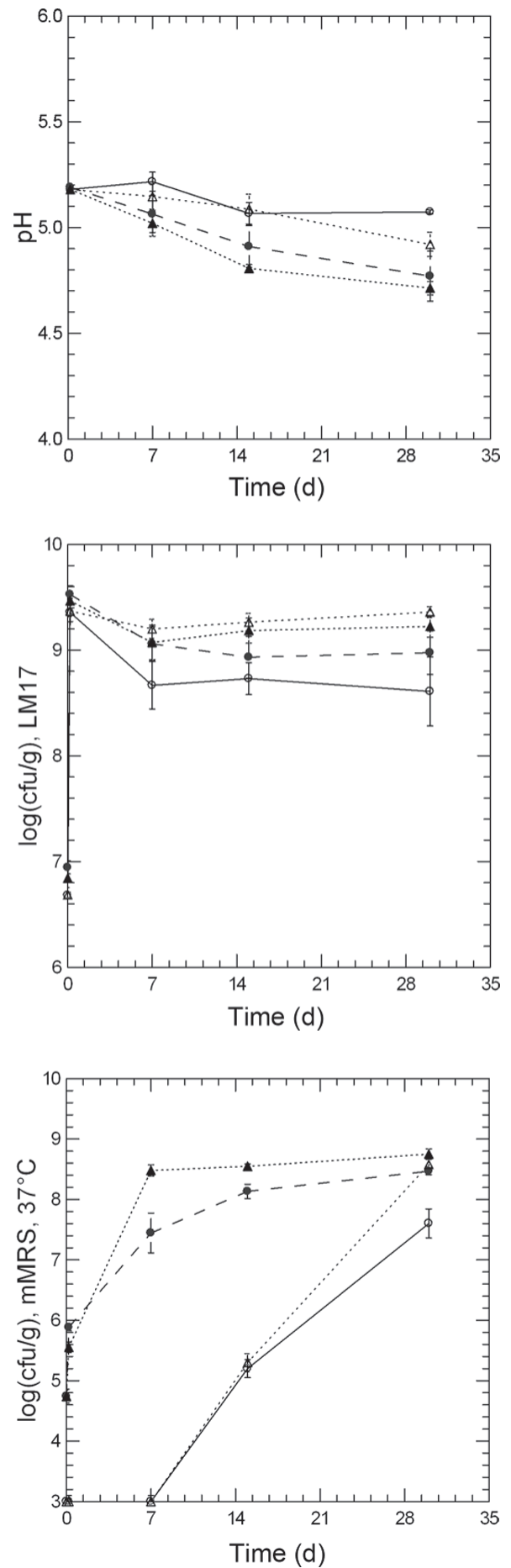

Figure 1. Evolution of $\mathrm{pH}$, primary starter counts (in LM17, $42^{\circ} \mathrm{C}$ ), and nonstarter lactic acid bacteria counts (in modified de Man Rogosa, and Sharpe medium with bromophenol blue; mMRS, $37^{\circ} \mathrm{C}$ ) in Scamorza cheeses during ripening. Cheese was made with 2 types of milk: 100\% Italian Friesian milk (F, circles) and mixed milk (M, triangles; $90 \% \mathrm{~F}+10 \%$ Jersey), and 2 types of starter culture: ST (open symbols), a defined Streptococcus thermophilus starter culture used alone; and ST+A (solid symbols), ST + an adjunct containing Lactococcus lactis, Lactobacillus paracasei, and Lactobacillus helveticus. Means and standard errors for 3 replicate cheese-making trials are shown. by NSLAB (Ong et al., 2006, 2007). However, this was clearly not the case in our study, because acetic acid was not detected. Streptococcus thermophilus is usually unable to ferment galactose (Iyer et al., 2010) and use of galactose-negative strains in the production of lowmoisture Mozzarella cheese results in residual galactose in the curd (Kindstedt et al., 2004). On the other hand, all strains used as adjuncts in this study were galactose positive and were able to grow with $2 \%$ (Lb. helveticus), $4 \%$ (Lc. lactis), or 6.5\% (Lb. paracasei) NaCl (Piraino et al., 2008). As a result, more lactic acid and a lower $\mathrm{pH}$ were found in cheese produced with adjuncts as well as a higher concentration of D-lactic acid produced by Lb. helveticus and Lb. paracasei. Di Cagno et al. (2012) obtained similar results for Caciocavallo Pugliese produced with live adjuncts.

\section{Proteolysis}

The $\mathrm{pH}$ 4.6-soluble and $\mathrm{pH}$ 4.6-insoluble nitrogen fractions were obtained for cheeses at 15 and $30 \mathrm{~d}$ of ripening. The $\mathrm{pH}$ 4.6-insoluble nitrogen fraction was separated by urea-PAGE. Gel images are shown in Supplementary Figures S2 and S3 (http://dx.doi. org/10.3168/jds.2014-8554). Attempts at using a PLS discriminant analysis (PLS-DA) model to assess the effect of time, milk, and starter were unsuccessful. However, univariate ANOVA showed that the intensity of several bands was affected by the type of starter and type of milk. Starter affected the intensities of bands with relative front $(\mathbf{R F})$ 0.211, 0.262, 0.292, 0.55 (corresponding to $\alpha$-casein), 0.635 (likely corresponding to $\alpha_{\mathrm{S1} 1} \mathrm{CN}$ f24-199), 0.651, 0.714, 0.801, and 0.888. Type of milk affected bands with RF $0.211,0.391$, and 0.635 . Time of ripening affected bands with RF $0.147,0.211$, 0.454 , and 0.635 . A PCA was carried out on the correlation matrix of relative band intensities, and the first 3 factors explained $75.7 \%$ of the variance. Score and loading plots are shown in Figure 4. High variability among replicate cheese-making trials was evident. Analysis of variance was carried out on the factor scores and showed that factor 1 was significantly affected by time $(P=0.001$, with lower values at $30 \mathrm{~d})$ and starter $(P=$ 0.03 , with lower values with the adjunct), factor 2 was significantly affected by time $(P=0.0006$, with lower average values at $30 \mathrm{~d})$, and factor 3 by milk type $(P=$ 0.003, with lower values for the mix).

The TNBS method was used to estimate total AA content of cheese. No significant differences were found at $15 \mathrm{~d}$, whereas the effect of the adjunct culture (with more secondary proteolysis in cheeses made with the adjunct) and block (with more proteolysis in cheeses made in the third cheese-making day) were significant. Proteolysis is one of the most important phenomena 


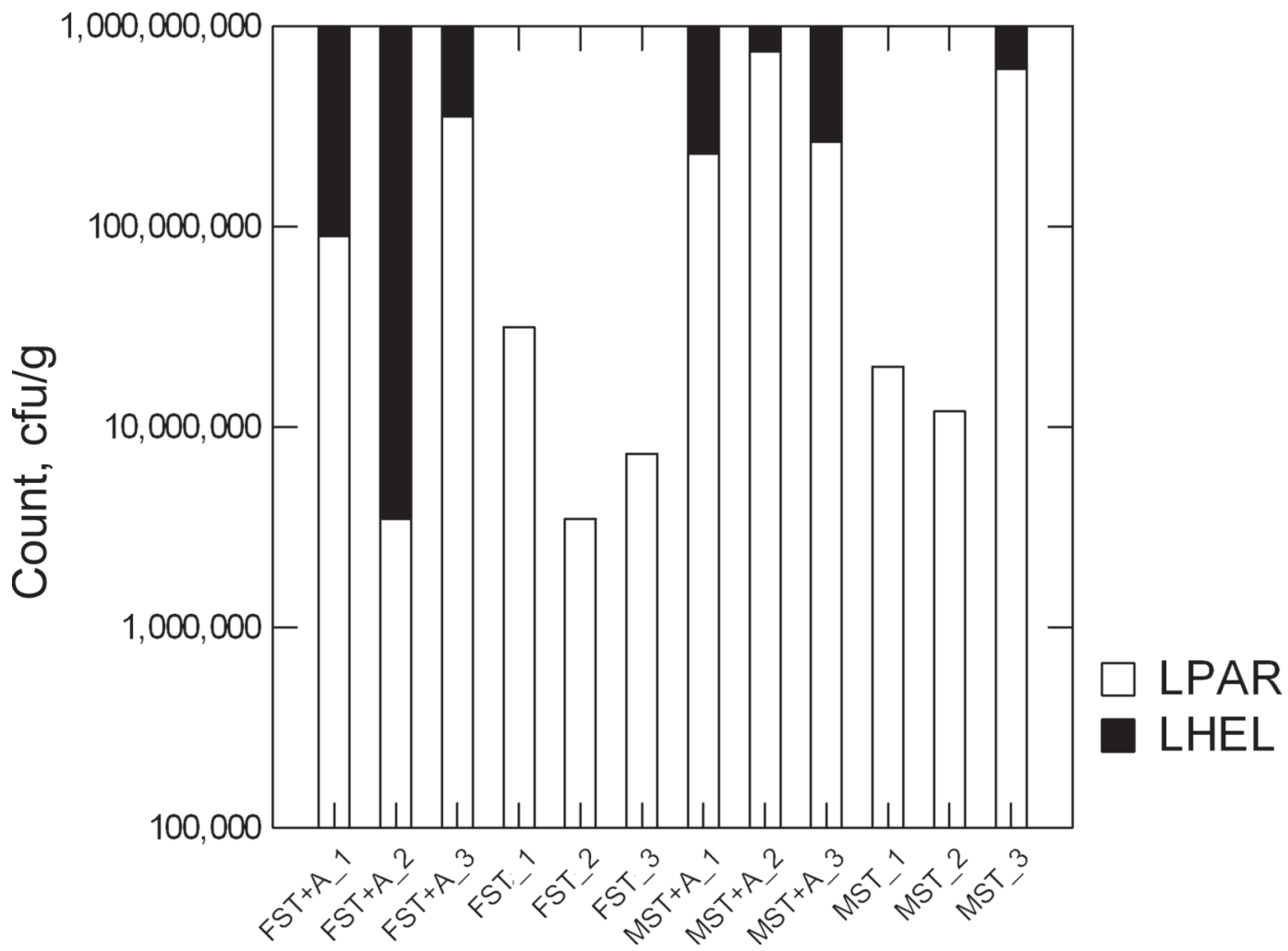

Figure 2. Stacked bar plot showing the presumptive counts of adjunct species recovered in Scamorza cheese after $30 \mathrm{~d}$ of ripening. Cheese was made with 2 types of milk: 100\% Italian Friesian milk (F) and mixed milk (M; $90 \%$ F $+10 \%$ Jersey), and 2 types of starter culture: ST, a defined Streptococcus thermophilus starter culture used alone; and ST+A, ST + an adjunct containing Lactococcus lactis, Lactobacillus paracasei, and Lactobacillus helveticus; the 4 treatments were FST, FST+A, MST, and MST+A. LPAR $=$ Lb. paracasei, LHEL $=$ Lb. helveticus; Lc. lactis was below the sensitivity of the method and it is not shown. The values for the 3 replicate cheese-making trials are shown.

during cheese ripening (Upadhyay et al., 2004), and adjunct cultures are often used to increase it because of their proteolytic and peptidolytic activity (El Soda et al., 2000; Chamba and Irlinger, 2004). Although significant proteolysis is only found in ripened pasta filata cheeses, such as Provolone and Caciocavallo (De Angelis and Gobbetti, 2011), proteolysis is also important in short-ripened varieties, including low-moisture Mozzarella cheese, in which it affects the functional properties of the cheese (Kindstedt et al., 2004) because of its effect on functional properties. Although adjuncts rarely contribute to primary proteolysis in cheese (Di Cagno et al., 2006; Ciocia et al., 2013), differences were found in the urea-PAGE profiles of Caciocavallo Pugliese cheese produced with or without adjunct cultures at $30 \mathrm{~d}$ (Di Cagno et al., 2012). However, it was not clear if the differences were due to direct or indirect effects. Perna et al. (2014) found that milk type (Holstein vs. Italian Brown) significantly affected primary proteolysis in Caciocavallo cheese and attributed the differences to differences in $\mathrm{pH}$ and moisture. In our study, $\mathrm{pH}$ and, to a lesser extent, moisture differences due to adjunct addition possibly affected the residual activity of plasmin. Plasmin is likely to be the main proteolytic enzyme in pasta filata cheeses (Gobbetti et al., 2002) because chymosin is usually inactivated at high temperatures (Hayes et al., 2002), but little or no degradation of $\beta$-casein was observed in urea-PAGE gels (Supplementary Figures S2a and S2b; http:// dx.doi.org/10.3168/jds.2014-8554). However, residual chymosin activity may be present in some pasta filata cheeses stretched at low temperatures (De Angelis and Gobbetti, 2011), which may have caused the limited degradation of $a_{S_{1}}$-casein observed in our study.

The amount of total AA estimated by the TNBS method in Scamorza cheese after $30 \mathrm{~d}$ of ripening was substantially lower (from 13 to $21 \mathrm{mg} / \mathrm{g}$ ) than that found in ripened pasta filata cheeses (De Angelis and Gobbetti, 2011; Di Cagno et al., 2012), likely because of the short ripening time. However, adjuncts greatly increased the amount of free AA. Adjunct starters are known to contribute to the release of free AA in several cheeses (El Soda et al., 2000), and the addition of adjuncts or attenuated adjuncts has been shown to substantially increase the amount of total AA in Caciocavallo Pugliese cheese ripened for 2 mo. Albenzio 


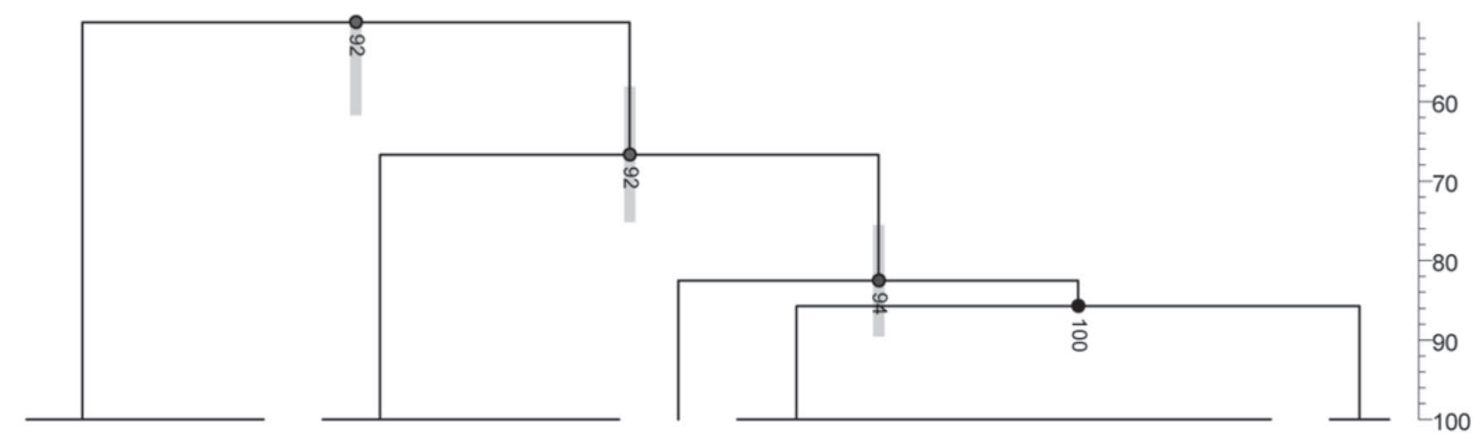

Lb. plantarum

\section{E. foecium \\ Lb. helveticus \\ E. foecalis \\ Lc. lactis \\ St. thermophilus}

Lb. paracasei

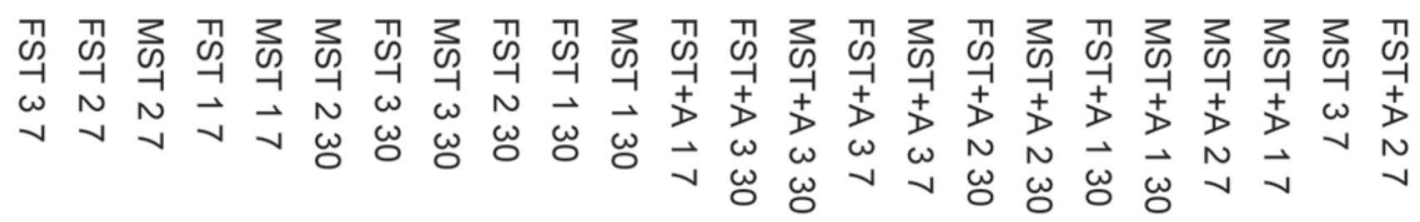

Figure 3. Dendrogram showing the similarity relationships (Dice coefficient was used and clustering was performed using unweighted pair group method with averages, UPGMA) among PCR-denaturing gradient gel electrophoresis patterns of the V3 region of 16S rDNA extracted from Scamorza cheese at 7 and $30 \mathrm{~d}$ of ripening. Cheese was made with 2 types of milk: 100\% Italian Friesian milk (F) and mixed milk (M; 90\% $\mathrm{F}+10 \%$ Jersey), and 2 types of starter culture: ST, a defined Streptococcus thermophilus starter culture used alone; and ST $+\mathrm{A}, \mathrm{ST}+$ an adjunct containing Lactococcus lactis, Lactobacillus paracasei, and Lactobacillus helveticus; the 4 treatments were FST, FST+A, MST, and MST+A. The identity of bands (Lb. paracasei, Enterococcus faecium, Lb. helveticus, Enterococcus faecalis, Lc. lactis, and S. thermophilus) and the patterns for the 3 replicate cheese-making trials are shown; values at nodes are bootstrapped confidence values.

et al. (2013b) found that even the addition of probiotic cultures (Bifidobacterium longum and Bifidobacterium lactis or Lactobacillus acidophilus) affected both primary and secondary proteolysis in ewe milk Scamorza cheese ripened for $15 \mathrm{~d}$. Both species were used at a very high inoculum level $(2 \%)$ and their addition resulted in a lower $\mathrm{pH}$ in cheese. Because it is unlikely that the probiotic strains grew in cheese, the effect may have been largely indirect.

\section{Volatile Compounds}

Headspace analysis of cheese was performed using an electronic nose with 10 sensors. Although within each replicate cheese-making trial and time, the built-in soft- ware of the electronic nose was able to clearly separate the treatments based on milk and starter, separation was poor when all samples (for each of which 3 replicate measurements were performed) were included. A PCA was performed on the correlation matrix of sensor responses and the results are shown in Figure 5. As before, variability between cheese-making trials obscured the pattern. However, ANCOVA showed that no sensor was significantly affected by milk type, whereas 6 sensors were significantly affected by starter and time $(P$ $<0.01$; sensors W1C, W5C, W3C, W5S, W1W, W2W) and 2 by time only (sensors W1S, W3S).

A PLS-discriminant analysis was also used to evaluate the effect of time, starter, and milk type on response. Cross-validation $\mathrm{R}^{2}$ values were generally low 


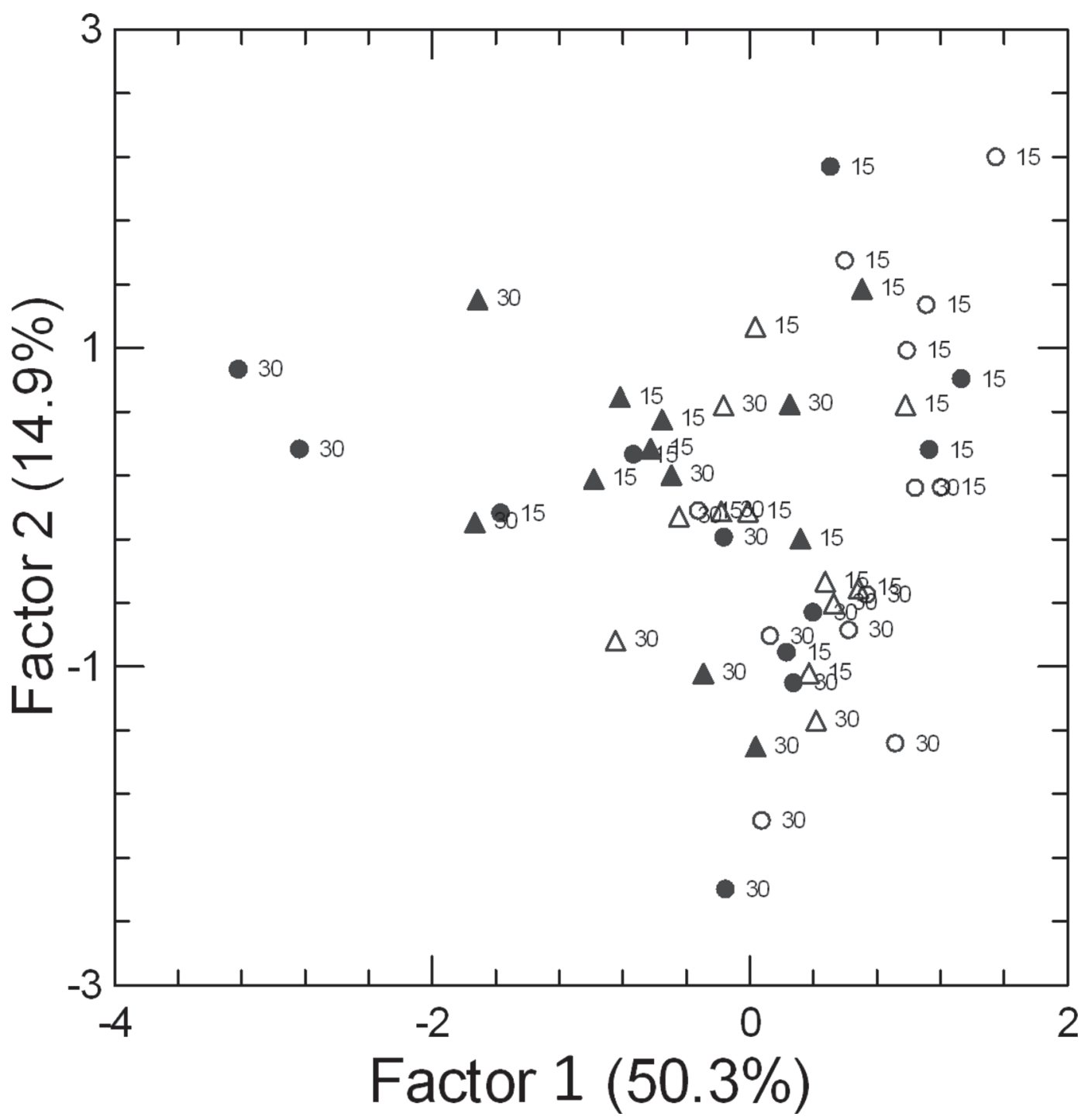

Figure 4. Score and loading plots for the principal component analysis carried out on the correlation matrix of relative surfaces of bands detected by urea-PAGE of $\mathrm{pH}$ 4.6-insoluble nitrogen fraction extracted from Scamorza cheese at 15 and $30 \mathrm{~d}$ of ripening. Cheese was made with 2 types of milk: 100\% Italian Friesian milk (F, circles) and mixed milk (M, triangles; $90 \% \mathrm{~F}+10 \%$ Jersey), and 2 types of starter culture: ST (open symbols), a defined Streptococcus thermophilus starter culture used alone; and ST+A (solid symbols), ST + an adjunct containing Lactococcus lactis, Lactobacillus paracasei, and Lactobacillus helveticus. Numerals indicate 15 or $30 \mathrm{~d}$ of ripening.

(0.55-0.60), but the same sensors whose response was significantly affected by starter and time in ANCOVA were significantly affected in the PLS analysis.

Different species of lactic acid bacteria used as adjuncts, including those used in our study, have been shown to affect the volatile compounds of several cheeses (Ayad et al., 2000; Lee et al., 2007; Van Hoorde et al., 2010). Sensor arrays have been widely used to evaluate the authenticity and quality of foods (Reid et al., 2006), including cheese (Ampuero and Bosset, 2003); to screen lactic acid bacteria for aroma production (Marilley et al., 2004; Gutiérrez-Méndez et al., 2008); and to evaluate the effect of adjunct in Swiss cheese (Kocaoglu-
Vurma et al., 2008). Although electronic noses lack selectivity, they are a fast and relatively inexpensive tool to assess cheese aroma, compared with GC-MS. Because of their multivariate nature, electronic nose data are treated by multivariate statistical methods, including PCA, discriminant analysis, and artificial neural networks, and the purpose is often discrimination of groups rather than inference on the effect of design variables. Although it is difficult to compare our data with those of other studies because of differences in the set-up and type of sensors, we confirmed that addition of adjuncts significantly affects the aroma of a pasta filata cheese even over short ripening times. 


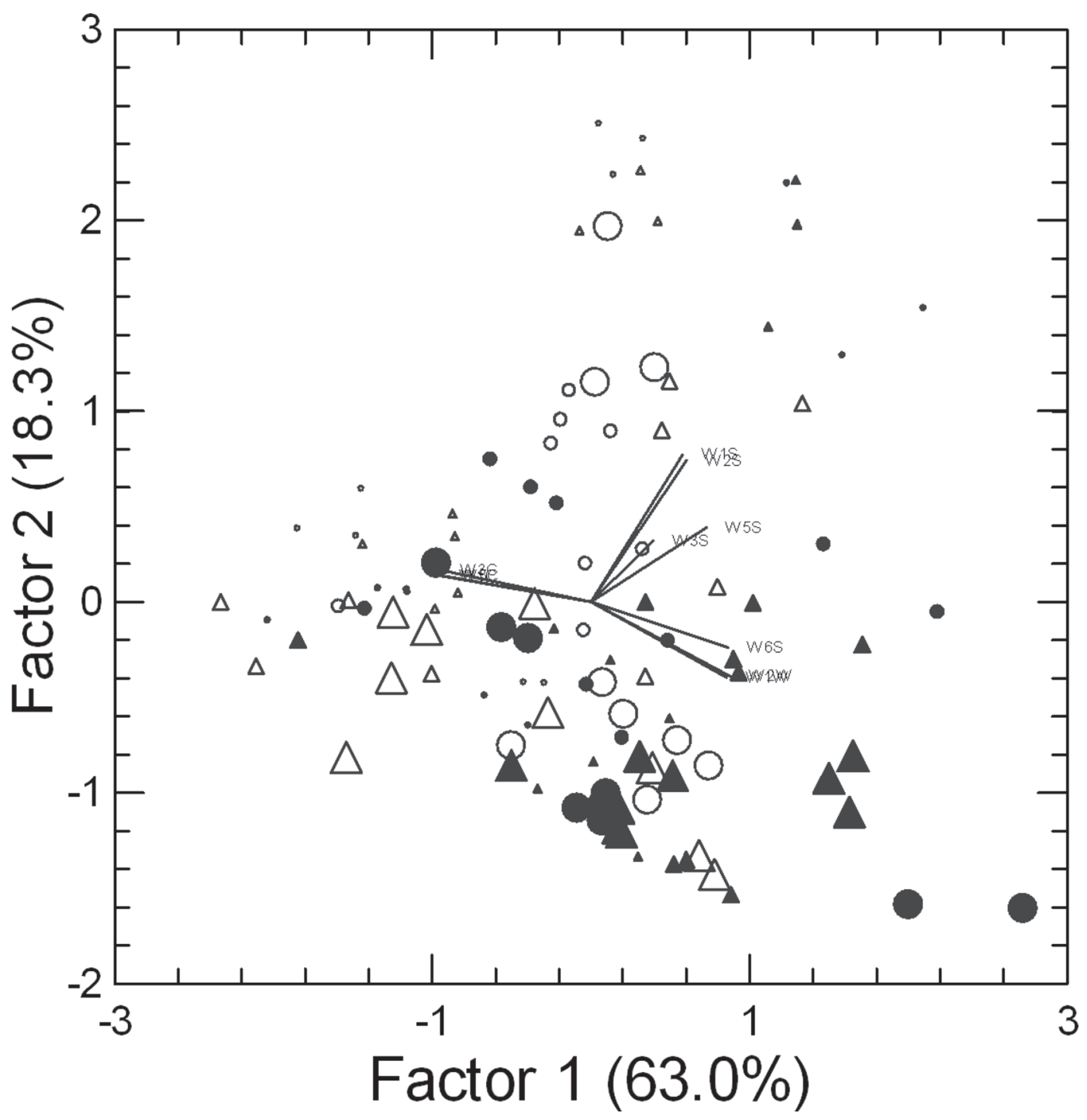

Figure 5. Score and loading plot for the principal component analysis carried out on the correlation matrix of responses of sensors (W numbers) of an electronic nose to the headspace volatile organic compounds from Scamorza cheese made with 2 types of milk: 100\% Italian Friesian milk (F, circles) and mixed milk (M, triangles; $90 \% \mathrm{~F}+10 \%$ Jersey), and 2 types of starter culture: ST (open symbols), a defined Streptococcus thermophilus starter culture used alone; and ST+A (solid symbols), ST + an adjunct containing Lactococcus lactis, Lactobacillus paracasei, and Lactobacillus helveticus at 7, 15 and $30 \mathrm{~d}$ of ripening. The size of the symbols is proportional to ripening time.

Because metal oxide semiconductor sensors have low specificity, it is impossible to correlate their response with the production of specific volatile aroma compounds by the adjuncts. However, the sensors that were most affected by use of adjuncts and milk type in our study were reported to have a broad range of response (W5S, W1S) or to respond to aromatic (W1C, W3C, W5C, W2W) or nonpolar organic compounds (W5C, W3S), to sulfur-containing organic compounds (W1W), or to terpenes (W1W) (Baietto et al., 2013). Organic compounds belonging to these classes are frequently found in the volatile organic fraction of cheese (Marilley and Casey, 2004) and may derive from either milk or starter culture activity (including metabolism of AA).
An attempt to identify the volatile organic compounds by dynamic headspace gas chromatography was carried out on cheese samples at 15 and $30 \mathrm{~d}$ of ripening using the techniques described by Fedele et al. (2005). Unfortunately, due to high variability between cheese-making trials, no significant difference was found as a function of milk type, use of adjunct, or time, and it is therefore impossible to identify the contribution of adjuncts and milk type on individual or groups of aroma compounds.

\section{CONCLUSIONS}

The addition of a complex adjunct and, to a lesser extent, the addition of a small amount of Jersey cow 
milk to Italian Friesian milk significantly affected composition, microbiological properties, proteolysis, and volatile compound profile in a semi-hard pasta filata cheese, Scamorza, produced using a $S$. thermophilus primary starter, over a relatively short $(30 \mathrm{~d})$ ripening time. Only 2 of the components of the adjunct ( $L b$. helveticus and $L b$. paracasei) were consistently found in cheese, and the most noticeable effects were on $\mathrm{pH}$ and release of free AA, whereas the effect on primary proteolysis was probably indirect. Although the changes caused by the addition of the adjunct are not necessarily desirable for all consumers, this work confirms that adjuncts can be used to accelerate ripening; manipulate cheese chemical, microbiological, and volatile properties; and differentiate the product.

\section{ACKNOWLEDGMENTS}

This work was co-funded by European Union (Brussels, Belgium) and Regione Basilicata (Potenza, Italy; FESR Misura 124HC QUALIFORM).

\section{REFERENCES}

Adler-Nissen, J. 1979. Determination of the degree of hydrolysis of food protein hydrolysates by trinitrobenzenesulfonic acid. J. Agric. Food Chem. 27:1256-1262.

Albenzio, M., A. Santillo, M. Caroprese, A. Braghieri, A. Sevi, and F. Napolitano. 2013a. Composition and sensory profiling of probiotic Scamorza ewe milk cheese. J. Dairy Sci. 96:2792-2800. http:// dx.doi.org/10.3168/jds.2012-6273.

Albenzio, M., A. Santillo, M. Caroprese, D. Ruggieri, F. Napolitano, and A. Sevi. 2013b. Physicochemical properties of Scamorza ewe milk cheese manufactured with different probiotic cultures. J. Dairy Sci. 96:2781-2791. http://dx.doi.org/10.3168/jds.20126218.

Ampuero, S., and J. Bosset. 2003. The electronic nose applied to dairy products: A review. Sensor Actuat. Biol. Chem. 94:1-12.

Aponte, M., V. Fusco, R. Andolfi, and S. Coppola. 2008. Lactic acid bacteria occurring during manufacture and ripening of Provolone del Monaco cheese: Detection by different analytical approaches. Int. Dairy J. 18:403-413.

Ayad, E., A. Verheul, J. Wouters, and G. Smit. 2000. Application of wild starter cultures for flavour development in pilot plant cheese making. Int. Dairy J. 10:169-179.

Baietto, M., L. Pozzi, A. D. Wilson, and D. Bassi. 2013. Evaluation of a portable MOS electronic nose to detect root rots in shade tree species. Comput. Electron. Agric. 96:117-125. http://dx.doi. org/10.1016/j.compag.2013.05.002.

Baruzzi, F., A. Matarante, M. Morea, and P. S. Cocconcelli. 2002. Microbial community dynamics during the Scamorza Altamurana cheese natural fermentation. J. Dairy Sci. 85:1390-1397.

Blakesley, R. W., and J. A. Boezi. 1977. A new staining technique for proteins in polyacrylamide gels using Coomassie Brilliant Blue G250. Anal. Biochem. 82:580-582.

Braghieri, A., N. Piazzolla, A. Romaniello, F. Paladino, A. Ricciardi, and F. Napolitano. 2015. Effect of adjuncts on sensory properties and consumer liking of Scamorza cheese. J. Dairy Sci. 98:14791491. $10.3168 /$ jds.2014-8555.

Chamba, J.-F., and F. Irlinger. 2004. Secondary and adjunct cultures. Pages 191-206 in Cheese: Chemistry, Physics and Microbiology. Vol. 1. P. F. Fox, P. L. H. McSweeney, T. M. Cogan, and T. P. Guinee ed., Elsevier, London, UK.
Ciocia, F., P. L. H. McSweeney, P. Piraino, and E. Parente. 2013. Use of dairy and non-dairy Lactobacillus plantarum, Lactobacillus paraplantarum and Lactobacillus pentosus strains as adjuncts in cheddar cheese. Dairy Sci. Technol. 93:623-640. http://dx.doi. org/10.1007/s13594-013-0131-8.

Coppola, S., V. Fusco, R. Andolfi, M. Aponte, G. Blaiotta, D. Ercolini, and G. Moschetti. 2006. Evaluation of microbial diversity during the manufacture of Fior di Latte di Agerola, a traditional raw milk pasta-filata cheese of the Naples area. J. Dairy Res. 73:264-272. http://dx.doi.org/10.1017/S0022029906001804.

Cronin, T., M. Ziino, C. Condurso, P. McSweeney, S. Mills, R. P. Ross, and C. Stanton. 2007. A survey of the microbial and chemical composition of seven semi-ripened Provola dei Nebrodi Sicilian cheeses. J. Appl. Microbiol. 103:1128-1139.

De Angelis, M., and M. Gobbetti. 2011. Pasta-filata cheeses: Traditional pasta-filata cheese. Pages 745-752 in Encyclopedia of Dairy Sciences. Vol. 1. 2nd ed. J. W. Fuquay, P. F. Fox, and P. L. H. McSweeney, ed. Academic Press, San Diego, CA

De Filippis, F., A. La Storia, G. Stellato, M. Gatti, and D. Ercolini. 2014. A selected core microbiome drives the early stages of three popular italian cheese manufactures. PLoS ONE 9:e89680 http:// dx.doi.org/10.1371/journal.pone.0089680.

De Marchi, M., G. Bittante, R. Dal Zotto, C. Dalvit, and M. Cassandro. 2008. Effect of Holstein Friesian and Brown Swiss breeds on quality of milk and cheese. J. Dairy Sci. 91:4092-4102. http:// dx.doi.org/10.3168/jds.2007-0788.

Di Cagno, R., I. De Pasquale, M. De Angelis, and M. Gobbetti. 2012. Accelerated ripening of Caciocavallo Pugliese cheese with attenuated adjuncts of selected nonstarter lactobacilli. J. Dairy Sci. 95:4784-4795. http://dx.doi.org/10.3168/jds.2011-5283.

Di Cagno, R., M. Quinto, A. Corsetti, F. Minervini, and M. Gobbetti. 2006. Assessing the proteolytic and lipolytic activities of single strains of mesophilic lactobacilli as adjunct cultures using a Caciotta cheese model system. Int. Dairy J. 16:119-130.

El Soda, M., S. Madkor, and P. S. Tong. 2000. Adjunct cultures: Recent developments and potential significance to the cheese industry. J. Dairy Sci. 83:609-619.

Ercolini, D., G. Frisso, G. Mauriello, F. Salvatore, and S. Coppola. 2008. Microbial diversity in natural whey cultures used for the production of Caciocavallo Silano PDO cheese. Int. J. Food Microbiol. 124:164-170.

Ercolini, D., G. Mauriello, G. Blaiotta, G. Moschetti, and S. Coppola. 2004. PCR-DGGE fingerprints of microbial succession during a manufacture of traditional water buffalo mozzarella cheese. J Appl. Microbiol. 96:263-270.

Fedele, V., R. Rubino, S. Claps, L. Sepe, and G. Morone. 2005. Seasonal evolution of volatile compounds content and aromatic profile in milk and cheese from grazing goats. Small Rumin. Res. 59:273-279.

Fox, P. F. 1963. Potentiometric determination of salt in cheese. J. Dairy Sci. 46:744-745.

Gobbetti, M., M. Morea, F. Baruzzi, M. Corbo, A. Matarante, T. Considine, R. Di Cagno, T. Guinee, and P. F. Fox. 2002. Microbiological, compositional, biochemical and textural characterisation of Caciocavallo Pugliese cheese during ripening. Int. Dairy J. $12: 511-523$

Guinee, T. P., and P. F. Fox. 2004. Salt in cheese: Physical, chemical and biological aspects. Pages 207-259 in Cheese: Chemistry, Physics and Microbiology. Vol. 1. P. F. Fox, P. L. H. McSweeney, T. M. Cogan, and T. P. Guinee, ed. Elsevier, London, UK.

Gutiérrez-Méndez, N., B. Vallejo-Cordoba, A. F. González-Córdova, G. V. Nevárez-Moorillón, and B. Rivera-Chavira. 2008. Evaluation of aroma generation of Lactococcus lactis with an electronic nose and sensory analysis. J. Dairy Sci. 91:49-57. /http://dx.doi. org/10.3168/jds.2007-0193.

Hayes, M. G., J. C. Oliveira, P. L. H. McSweeney, and A. L. Kelly. 2002. Thermal inactivation of chymosin during cheese manufacture. J. Dairy Res. 69:269-279.

IDF (International Dairy Federation). 1982. International Standard 4A: Cheese and processed cheese - Determination of the total solids content (reference method). IDF, Brussels, Belgium. 
IDF (International Dairy Federation). 1996. Milk: Determination of the fat content (Rose Gottlieb gravimetric method). International Standard 1d. IDF, Brussels, Belgium.

Iyer, R., S. Tomar, T. Uma Maheswari, and R. Singh. 2010. Streptococcus thermophilus strains: Multifunctional lactic acid bacteria. Int. Dairy J. 20:133-141. http://dx.doi.org/10.1016/j.idairyj.2009.10.005.

Kenny, O., R. FitzGerald, G. O'Cuinn, T. Beresford, and K. Jordan. 2006. Autolysis of selected Lactobacillus helveticus adjunct strains during Cheddar cheese ripening. Int. Dairy J. 16:797-804.

Kindstedt, P. 2004. Mozzarella cheese: 40 years of scientific advancement. Int. J. Dairy Technol. 57:85-90.

Kindstedt, P., M. Carić, and S. Milanović. 2004. Pasta filata cheeses. Pages 251-277 in Cheese: Chemistry, Physics and Microbiology. Vol. 2. P. F. Fox, P. L. H. McSweeney, T. M. Cogan, and T. P. Guinee, ed. Elsevier, London, UK.

Kocaoglu-Vurma, N. A., W. J. Harper, M. A. Drake, and P. D. Courtney. 2008. Microbiological, chemical, and sensory characteristics of Swiss cheese manufactured with adjunct Lactobacillus strains using a low cooking temperature. J. Dairy Sci. 91:2947-2959. http://dx.doi.org/10.3168/jds.2007-0592.

Kuchroo, C. N., and P. F. Fox. 1982. Soluble nitrogen in Cheddar cheese; comparison of extraction procedures. Milchwissenschaft $37: 331-335$.

Lee, B., K. Kilcawley, J. Hannon, S. Park, M. Wilkinson, and T. P. Beresford. 2007. The use of viable and heat-shocked Lactobacillus helveticus DPC 4571 in enzyme-modified cheese production. Food Biotechnol. 21:129-143.

Lee, H. M., and Y. Lee. 2008. A differential medium for lactic acidproducing bacteria in a mixed culture. Lett. Appl. Microbiol. 46:676-681.

Marilley, L., S. Ampuero, T. Zesiger, and M. G. Casey. 2004. Screening of aroma-producing lactic acid bacteria with an electronic nose. Int. Dairy J. 14:849-856. http://dx.doi.org/10.1016/j.idairyj.2004.02.013.

Marilley, L., and M. G. Casey. 2004. Flavours of cheese products: metabolic pathways, analytical tools and identification of producing strains. Int. J. Food Microbiol. 90:139-159.

Morea, M., A. Matarante, R. Di Cagno, F. Baruzzi, and F. Minervini. 2007. Contribution of autochthonous non-starter lactobacilli to proteolysis in Caciocavallo Pugliese cheese. Int. Dairy J. 17:525534

Ong, L., A. Henriksson, and N. P. Shah. 2006. Development of probiotic cheddar cheese containing Lactobacillus acidophilus, Lb. casei, $L b$. paracasei and Bifidobacterium spp. and the influence of these bacteria on proteolytic patterns and production of organic acid. Int. Dairy J. 16:446-456.
Ong, L., A. Henriksson, and N. P. Shah. 2007. Chemical analysis and sensory evaluation of cheddar cheese produced with Lactobacillus acidophilus, Lb. casei, Lb. paracasei or Bifidobacterium sp. Int. Dairy J. 17:937-945.

Perna, A., A. Simonetti, I. Intaglietta, and E. Gambacorta. 2014. Effects of genetic type, stage of lactation, and ripening time on Caciocavallo cheese proteolysis. J. Dairy Sci. 97:1909-1917. http:// dx.doi.org/10.3168/jds.2013-7288.

Petersen, B. L., R. I. Dave, D. J. McMahon, C. J. Oberg, and J. R. Broadbent. 2000. Influence of capsular and ropy exopolysaccharide-producing Streptococcus thermophilus on Mozzarella cheese and cheese whey. J. Dairy Sci. 83:1952-1956.

Piraino, P., T. Zotta, A. Ricciardi, P. McSweeney, and E. Parente. 2008. Acid production, proteolysis, autolytic and inhibitory properties of lactic acid bacteria isolated from pasta filata cheeses: A multivariate screening study. Int. Dairy J. 18:81-92.

Piraino, P., T. Zotta, A. Ricciardi, and E. Parente. 2005. Discrimination of commercial Caciocavallo cheeses on the basis of the diversity of lactic microflora and primary proteolysis. Int. Dairy J. $15: 1138-1149$

Quigley, L., Ó. O'Sullivan, T. P. Beresford, R. P. Ross, G. F. Fitzgerald, and P. D. Cotter. 2012. A comparison of methods used to extract bacterial DNA from raw milk and raw milk cheese. J. Appl. Microbiol. 113:96-105.

Randazzo, C. L., S. Torriani, A. Akkermans, W. de Vos, and E. Vaughan. 2002. Diversity, dynamics, and activity of bacterial communities during production of an artisanal Sicilian cheese as evaluated by $16 \mathrm{~S}$ rRNA analysis. Appl. Environ. Microbiol. 68:1882-1892

Reid, L., C. O'Donnell, and G. Downey. 2006. Recent technological advances for the determination of food authenticity. Trends Food Sci. Technol. 17:344-353.

Upadhyay, V. K., P. L. H. McSweeney, A. A. A. Magboul, and P. F. Fox. 2004. Proteolysis in cheese in cheese during ripening. Pages 391-433 in Cheese: Chemistry, Physics and Microbiology. Vol. 1. P. F. Fox, P. L. H. McSweeney, T. M. Cogan, and T. P. Guinee, ed., Elsevier, London, UK.

Van Hoorde, K., I. Van Leuven, P. Dirinck, M. Heyndrickx, K. Coudijzer, P. Vandamme, and G. Huys. 2010. Selection, application and monitoring of Lactobacillus paracasei strains as adjunct cultures in the production of Gouda-type cheeses. Int. J. Food Microbiol. 144:226-235. http://dx.doi.org/10.1016/j.ijfoodmicro.2010.05.007.

Yun, J. J., D. M. Barbano, L. J. Kiely, and P. S. Kinstedt. 1995. Mozzarella cheese: Impact of rod:coccus ratio on composition, proteolysis and functional properties. J. Dairy Sci. 78:751-760.

Yvon, M., and L. Rijnen. 2001. Cheese flavour formation by amino acid catabolism. Int. Dairy J. 11:185-201. 